\title{
VOICE ENABLED SPEED CONTROL OF AC MOTOR
}

\author{
Prabhu.S ${ }^{1}$, Sakulhameed.A ${ }^{2}$, Sureshkumar. ${ }^{3}$, Arun.S ${ }^{4}$ \\ ${ }^{1,2}$ \& 3 P.G. Scholar, Dept of PG-ES, PACET, Tamilnadu, India \\ ${ }^{4}$ Asst. professor, Dept of EEE, PACET, Tamilnadu, India
}

\begin{abstract}
Communication plays a major role in day today's life and can be used as a better tool in control systems. It deals with wire communication and is used to control the motor speed. Out of all mechanisms, microcontroller hardware description language proves to be efficient than al other mechanisms. Digital means of controlling gives accurate results compared to the approximation of analog systems. Embedded technology is a key role in integrating the different functions connected with it. This proposal generally reduces the manpower, operates efficiently and saves time without human involvement. With the advancements in technology, the existing systems are developed to have in built intelligence. Due to the technological development whether it is DC or AC machines the speed of the machine can be controlled by various methods. By means of the voice process the machine can be controlled depending upon the application wired or in order to transmit the signal the wireless communication can be used. By this way electrical technology is combined with communication technology and computer science. Now a day it is very important thing to reduce the manual error and manual operation.
\end{abstract}

Index Terms—voice recognition, PWM, shaded pole induction motor

\section{INTRODUCTION}

Nowadays many industries are using various technologies for speed control of the motor. They are very much interested in reducing the manual operations. So they are using different kind of methods in day to day activities. Our project also deals with reduction of manual operation by combining various technologies such as electric drives wireless communication and embedded technology. Here voice communication plays a major role in this project. We are using voice communication in different fields for various purposes. Motor speed can be varied by different speed control schemes at rotor side and stator side of the motor. In stator side we have voltage control, frequency control and pole changing method. In rotor side we have resistance control, slip power recovery method, pwm technique, etc. Pwm technique is a new one which mostly used for speed control. Now we are going to control the speed of the motor by voice recognition method. Small scale industries (SSI) play a vital role in shaping the economy of the country. This has special significance with reference to developing nations like India with contributes in terms of large scale employment generation and high labor to capital ratio. It is a means for making the best use of surplus human resource available in the country. They ensure the optimum utilization of locally available resources and cater to the needs of the local market. Thus SSI units contribute positively towards the industrialization process. The Indian small scale sector has a significant contribution in terms of both industrial production and export. It is emerged as a dynamic and vibrant sector economy[1].

\subsection{VOICE RECOGNITION METHOD}

Voice recognition is a technology in which the spoken words can be translated into a text format. In this some of the recognition system uses a training to convert a individual speakers section of text into the voice recognition system. This system observes the specific voice of the person and that voice is tuned by means of recognition, which results in accurate transcription. Speaker dependent system uses a training concept. Speaker independent system does not use a training concept. These concepts mainly concentrate on who is speaking rather than what they are speaking "Voice recognition" means "recognizing by voice", something humans do all the time over the phone. As soon as someone familiar says "hello" the listener can identify them by the sound of their voice alone[2].The project is designed with microphone, microcontroller, amplifier, pulse shaping circuit and driver circuit with relay. The voice signal is given as input to the microphone and its output is amplified using an amplifier. The amplified signal is given to the pulse shaping circuit. The pulse shaping circuit generates square pulses which are given to the microcontroller. The pulse waveform for switching ON \& OFF of the different electrical appliances used, are stored in the microcontroller. The microcontroller is programmed to compare the received pulse with the stored values and to activate the corresponding relay driver circuits of the electrical appliances. 


\subsection{CONCEPT OF VOICE RECOGNITION}

When the power supply is switched ON the LCD displays "VOICE BASED ELECTRICAL APPLIANCE". After few seconds they will disappear. The input voice command signal is given through microphone to voice recognition circuit. The input voice command signal is given through microphone to voice reorganization circuit. This circuit consists of an inverting amplifier, differential amplifier and voltage follower. The command signal from voice reorganization circuit is given to the pulse shaping circuit to convert the voice signal into pulses[3]. The converted pulses are given to the microcontroller. The microcontroller receives the pulse and is counted by the microcontroller in built counter and the corresponding count value is displayed in the LCD display. When the voice command signal is applied, the corresponding counted value is compared with the stored value. If it is matched the microcontroller sends the command signal to any one of the relay driver circuits and the corresponding relay driver circuit converts the received signal to energize or de-energize the relay coil The energize or de-energize of the relay coil turns ON or OFF the corresponding appliance connected through it. Now the LCD display displays the corresponding changes that had happened to the appliance connected to the relay. Until the next voice command signal is given the LCD display displays the corresponding changes[4].

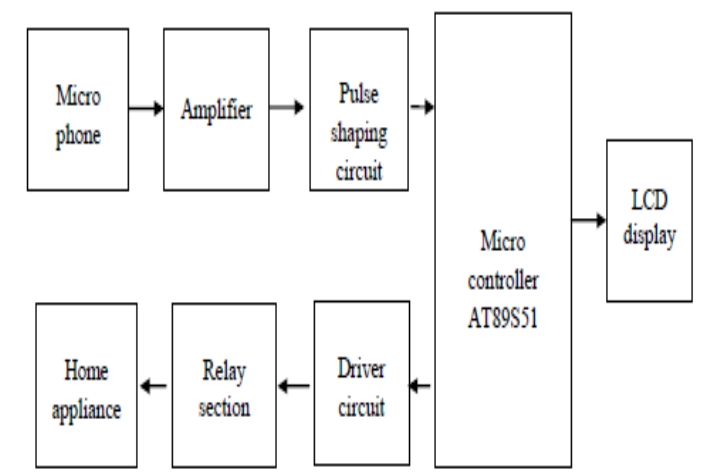

Fig 1. Block diagram of voice recognition control

\section{MODULE DESCRIPTION}

For voice controlled operation circuit is divided into two as follows.

1. Transmitting circuit.

2. Receiving circuit.

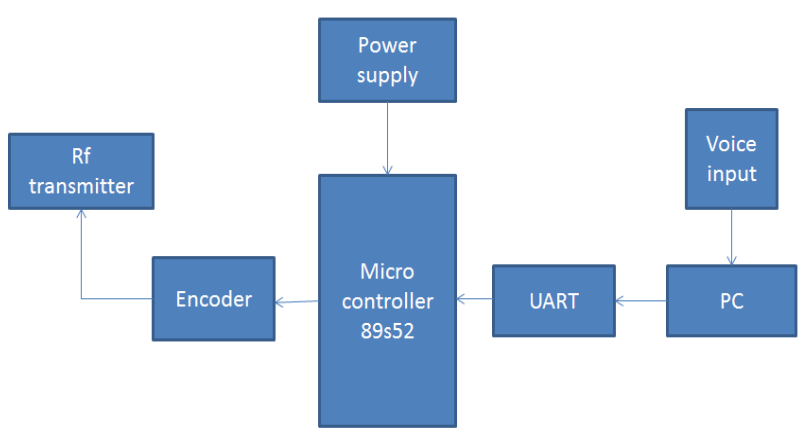

Fig 2.Transmitter block diagram

An encoder is a device, algorithm, circuit transducer software program, or person that converts information or code from one form into another. UART is used for serial communications over a computer or peripheral device serial port because it is integrated circuit. MICRO CONTROLLER AT89S51 is a low-power, highperformance CMOS 8-bit Microcomputer with $4 \mathrm{~K}$ bytes of Flash programmable and erasable read only memory (PEROM).

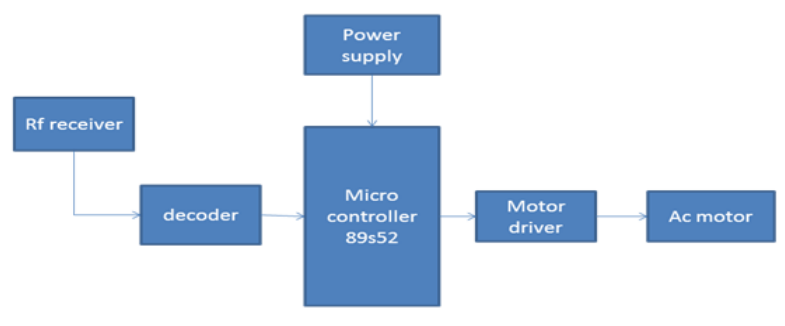

Fig 3.Receiver block diagram

A decoder is a device which does the reverse operation of an encoder, undoing the encoding so that the original information can be retrieved.

\section{RESULTS AND DISCUSSION}

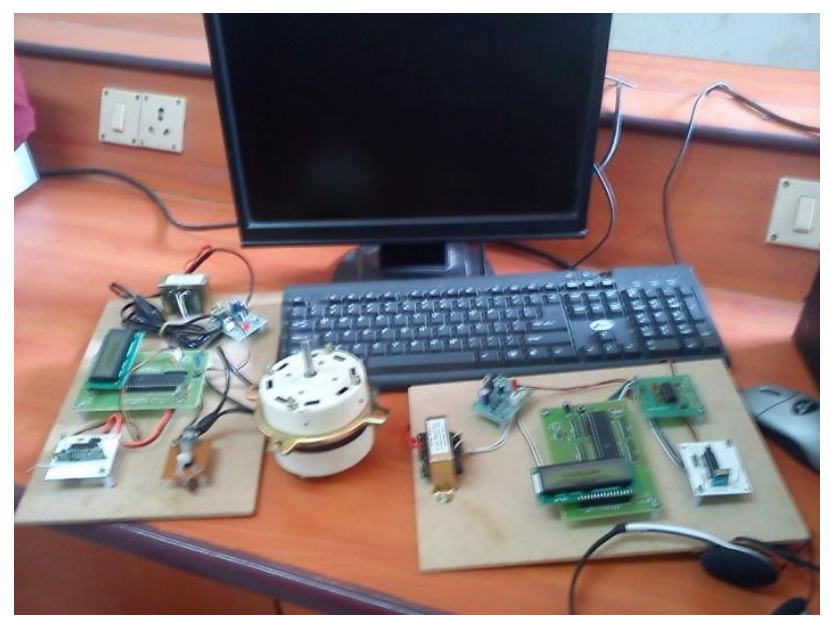

Fig 4. Experimental Setup 
Voice from the user is first analyzed by micro phone and is converted to a keyword such as A, B, C, D, E for a particular speech.

A stands for 'start',B stands for 'slow speed', C stands for 'medium speed', D stands for 'fast speed', E stands for 'stop[5]'.

By this way required voice signal is converted from voice recognizer as keywords and send to micro controller through UART.Then Universal Asynchronous Receiver and Transmitter transmits the signal from PC to micro controller as serial input. Micro controller has already programmed by the user for such keywords mentioned above. Here each keyword has unique programming loop. Then it should be transmitted. For this purpose signal should be encoded by the encoder. For example, keyword A is encoded as 0000 (for 4bit operation). Then it will be transmitted by the transmitter circuit at certain radio frequency range. It will cover the area about $10 \mathrm{~cm}$ for signal receiving operation[6],[7]. Each operation is indicated by the LCD display.

\subsection{SIMULATION MODULE}

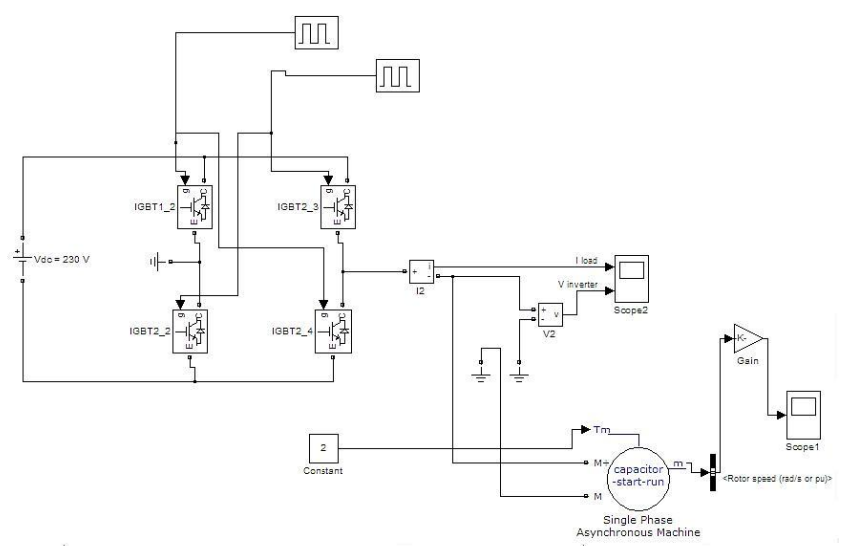

Fig 6. Simulation diagram

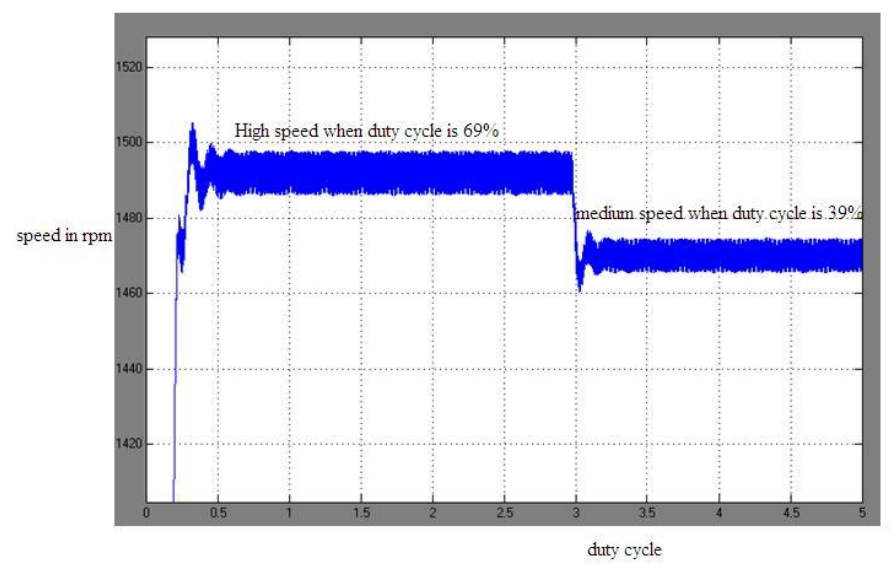

Fig 7. Simulation result

pulse generators generate pwm pulses which require speed controlling operation here. Simulation shows the variation of speed for different duty cycles. When duty cycle is high, average output voltage of the thyristor will be more. So motor operates at high speed. By reducing the duty cycle speed can be reduced.

\section{CONCLUSIONS}

The speed of the motor is controlled for five stages only. In future we can implement for maximum no of speeds by increasing the coding in micro controller. So that we can generate maximum number of pulses as per our requirement. In this work, shaded pole induction motor is used. In speed control process, dc motor is easier than ac motor since driver circuit design is very simple. But due to the availability of $\mathrm{AC}$ supply and considering the cost of the motor, $\mathrm{AC}$ motor is used.

\section{REFERENCES}

[1]. Sharma.P.K et al.,"Real time control of dc motor drive using speech recognition", power electronics(IICPE),2010 India international conference.

[2]. Gulbins.H et al., "use of voice controlled and computer assisted surgical system zeus for endoscopic coronary artery bypass grafting" 1999.

[3]. Bilmes.J.A et al., "evaluation of voice based cursor control techniques for assistive technology" 2008.

[4]. Landay.J.A et al., "a hands free voice driven drawing application for people with motor impairments" 2007.

[5]. Hughes.J.F et al., "voice as sound using non verbal voice input for interactive control" 2001.

[6]. Doran.M.V et al., "a voice operated tour planning system for autonomous mobile robots" 2010.

[7]. Feiner.S et al., "using prosodic features of speech and audio localization in graphical user interfaces" 2005.

\section{BIOGRAPHIES}

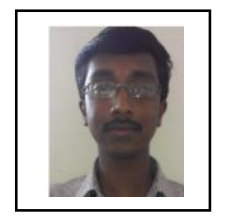

Prabhu.S received his B.E.,(Electrical and Electronics Engineering) degree from P.A College of engineering and technology in 2012, and pursuing M.E., (Power Electronics and Drives) degree in P.A College of Engineering and Technology Pollachi

Sakulhameed.A received his B.E.,(Electrical and Electronics Engineering) degree from Subramanya College of engineering and technology in 2009, and pursuing M.E., (Power Electronics and Drives) degree in P.A College of Engineering and Technology Pollachi 


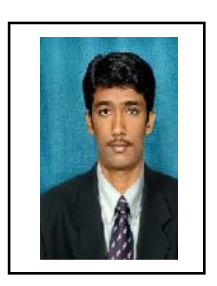

Sureshkumar.V received his

B.E.,(Electrical and Electronics

Engineering) degree from P.A

College of engineering and technology in 2012, and pursuing M.E., (Power Electronics and Drives) degree in P.A College of Engineering and Technology Pollachi

Arun.S received his B.E.,(Electrical and Electronics Engineering) degree from Sri Ramakrishna institute of engineering and technology in 2007, and received his M.E., (Power Electronics and Drives) degree from Anna university Coimbatore in 2010 and currently working as an asst.professor in P.A College of Engineering and Technology Pollachi 